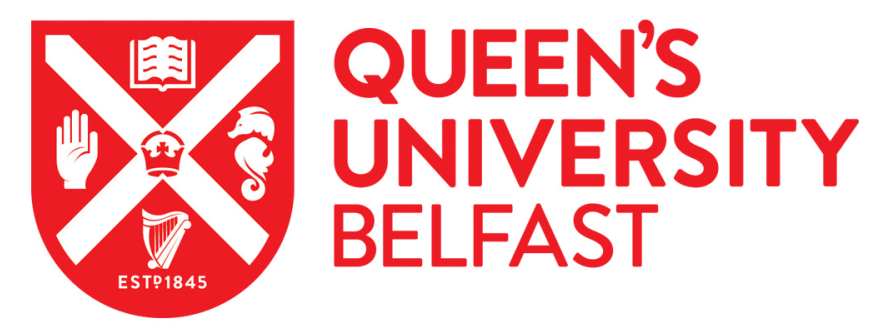

\title{
Lack of IL-1 Receptor Signaling Reduces Spontaneous Airway Eosinophilia in Juvenile Mice with Muco-Obstructive Lung Disease
}

Brown, R., Paulsen, M., Schmidt, S., Schaterrny, J., Frank, A., Hirtz, S., Delaney, R., Doherty, D., Hagner, M., Taggart, C., Weldon, S., \& Mall, M. A. (2020). Lack of IL-1 Receptor Signaling Reduces Spontaneous Airway Eosinophilia in Juvenile Mice with Muco-Obstructive Lung Disease. American Journal of Respiratory Cell and Molecular Biology, 63(3), 300-309. https://doi.org/10.1165/rcmb.2018-03590C

Published in:

American Journal of Respiratory Cell and Molecular Biology

Document Version:

Peer reviewed version

Queen's University Belfast - Research Portal:

Link to publication record in Queen's University Belfast Research Portal

Publisher rights

(c) 2019 by the American Thoracic Society. This work is made available online in accordance with the publisher's policies. Please refer to any applicable terms of use of the publisher.

\section{General rights}

Copyright for the publications made accessible via the Queen's University Belfast Research Portal is retained by the author(s) and / or other copyright owners and it is a condition of accessing these publications that users recognise and abide by the legal requirements associated with these rights.

Take down policy

The Research Portal is Queen's institutional repository that provides access to Queen's research output. Every effort has been made to ensure that content in the Research Portal does not infringe any person's rights, or applicable UK laws. If you discover content in the Research Portal that you believe breaches copyright or violates any law, please contact openaccess@qub.ac.uk. 


\section{Lack of IL-1 Receptor Signaling Reduces Spontaneous Airway Eosinophilia in Juvenile Mice with Muco-Obstructive Lung Disease}

Ryan Brown ${ }^{1}$, Michelle Paulsen ${ }^{1}$, Simone Schmidt ${ }^{1}$, Jolanthe Schatterny ${ }^{1}$, Angela Frank ${ }^{1}$, Stephanie Hirtz $^{1}$, Rebecca Delaney ${ }^{2}$, Declan Doherty ${ }^{2}$, Matthias Hagner ${ }^{1}$, Cliff Taggart ${ }^{2}$, Sinéad Weldon ${ }^{2}$ and Marcus A. Mall $1,3,4$

${ }^{1}$ Department of Translational Pulmonology, Translational Lung Research Centre Heidelberg (TLRC), German Center for Lung Research (DZL), University of Heidelberg, Heidelberg, Germany ${ }^{2}$ Airway Innate Immunity Research (AiiR) Group, Wellcome-Wolfson Institute for Experimental Medicine, School of Medicine, Dentistry and Biomedical Sciences, Queen's University Belfast, Belfast, Northern Ireland

${ }^{3}$ Department of Pediatric Pulmonology, Immunology and Intensive Care Medicine, CharitéUniversitätsmedizin Berlin, Berlin, Germany

${ }^{4}$ Berlin Institute of Health (BIH), Berlin, Germany

\section{Corresponding author:}

Marcus A. Mall, M.D., Department of Pediatric Pulmonology, Immunology and Intensive Care Medicine, Charité - Universitätsmedizin Berlin and Berlin Institute of Health (BIH), Augustenburger Platz 1, 13353 Berlin, Germany. Tel.: +49 30450566 131, Fax: +49 30450566 931, Email: Marcus.Mall@charite.de

Author contributions: Conception and design of the study: RB, MAM; Acquisition, analysis and interpretation of data: $\mathrm{RB}, \mathrm{SS}, \mathrm{JS}, \mathrm{AF}, \mathrm{SH}, \mathrm{MP}, \mathrm{RD}, \mathrm{DD}, \mathrm{MAM}$; Drafting the article or revising it critically for important intellectual content: RB, MP, RD, DD, MH, SW, CT, MAM.

Sources of support: This study was supported in part by grants from the German Federal Ministry of Education and Research (82DZL00401), the German Research Foundation (SFB-TR84 B08) and the Cystic Fibrosis Foundation (WELDON18G0). M.A.M. is supported by a grant from the Einstein Foundation Berlin (EP-2017-393).

Running title: Role of IL-1 receptor signaling in airway eosinophilia

This article has an online data supplement, which is accessible from this issue's table of content online at www.atsjournals.org. 


\section{ABSTRACT}

Previous studies demonstrated spontaneous type 2 airway inflammation with eosinophilia juvenile Scnn1b-Tg mice with muco-obstructive lung disease. Interleukin-1 receptor (IL-1R) signaling has been implicated in allergen-driven airways disease, however, its role in eosinophilic inflammation in mucoobstructive lung disease remains unknown. In this study, we examined the role of IL-1R signaling in the development of airway eosinophilia and type 2 inflammation in juvenile Scnn $1 b$-Tg mice. We determined effects of genetic deletion of $/ 11 r 1$ on eosinophil counts, transcript levels of key type 2 cytokines, markers of eosinophil activation and apoptosis, and tissue morphology in lungs of Scnn1b$\mathrm{Tg}$ mice at different time points during neonatal development. Further, we measured endothelial surface expression of intercellular adhesion molecule 1 (ICAM-1), an integrin involved in eosinophil transendothelial migration, and determined effects of eosinophil depletion using an anti-IL-5 antibody on lung morphology. Lack of IL-1R reduced airway eosinophilia and structural lung damage, but did not reduce levels of type 2 cytokines and associated eosinophil activation in Scnn $1 b$-Tg mice. Structural lung damage in Scnn1b-Tg mice was also reduced by eosinophil depletion. Lack of IL-1R was associated with reduced expression of ICAM-1 on lung endothelial cells and reduced eosinophil counts in lungs from Scnn1b-Tg mice. We conclude that IL-1R signaling is implicated in airway eosinophilia independent of type 2 cytokines in juvenile Scnn1b-Tg mice. Our data suggest that IL-1R signaling may be relevant in the pathogenesis of eosinophilic airway inflammation in muco-obstructive lung diseases, which may, in part, be mediated by ICAM-1 dependent transmigration of eosinophils into the lungs.

Keywords: Eosinophil, interleukin-1, migration, type 2 inflammation 


\section{INTRODUCTION}

Airway eosinophilia is an important phenotype in muco-obstructive lung diseases including asthma and chronic obstructive pulmonary disease (COPD) $(1,2)$. Airway eosinophils are key effector cells in allergic asthma mediating airway hyperresponsiveness, inflammation and remodeling through the release of pro-inflammatory mediators (3). Additionally, airway eosinophilia is associated with more severe lung disease in patients with COPD $(4,5)$. Scnn1b-Tg mice present with spontaneous mucoobstructive lung disease caused by airway surface dehydration and reduced mucociliary clearance (MCC) leading to airway mucus obstruction, chronic inflammation and structural lung damage (6-9). Previous longitudinal studies of $S c n n 1 b$-Tg mice demonstrated that during the first weeks of life this muco-obstructive phenotype is associated with the development of spontaneous eosinophilic inflammation and type 2 inflammation (9-11). Recent studies suggest that this airway eosinophilia may be in part triggered by allergen retention (12), but the pathogenesis of eosinophilic inflammation and its relationship to type 2 inflammation remain incompletely understood.

Previous studies in mouse models of experimental asthma identified a role of interleukin-1 receptor (IL-1R) signaling in the pathogenesis of airway eosinophilia and type 2 inflammation in allergeninduced airways disease (13-15). In a house dust mite (HDM)-induced model of allergic airway disease it was shown that HDM exposure triggers release of interleukin-1 $\alpha($ IL-1 $\alpha)$ from airway epithelial cells, which acts in an autocrine manner to induce the release of granulocyte-macrophage colonystimulating factor (GM-CSF) and interleukin-33 (IL-33) that in turn activate dendritic cells to drive adaptive type 2 immunity (16). In a previous study, we identified a role of IL-1R signaling in the pathogenesis of neutrophilic airway inflammation in in Scnn1b-Tg mice (17). Specifically, we found that airway mucus obstruction triggers hypoxic necrosis of a subset of airway epithelial cells leading to the release of IL-1 $\alpha$ (17-20). Further, we showed that IL-1R signaling contributes to the development of neutrophilic airway inflammation, mucus plugging and structural lung damage in this model of muco-obstructive lung disease (17). However, the role of IL-1R signaling in the pathogenesis 
of spontaneous airway eosinophilia and type 2 inflammation observed in juvenile Scnn1b-Tg mice remains unknown.

The aim of this study was, therefore, to examine the role IL-1R signaling in the development of spontaneous airway eosinophilia and type 2 inflammation present in juvenile Scnn $1 b$-Tg mice. To achieve this goal, we determined effects of genetic deletion of $/ 11 r 1$ on eosinophil counts in bronchoalveolar lavage (BAL) and lung tissue, transcript levels of key type 2 cytokines and eosinophil chemoattractants $(I / 13, I 15, C c / 11, C c / 24)$, eosinophil activation and apoptosis, eosinophil granule protein levels and tissue morphology in lungs of wild-type (WT) and Scnn1b-Tg mice at different time points during neonatal development. Further, we measured endothelial surface expression of intercellular adhesion molecule 1 (ICAM-1), an integrin involved in eosinophil transmigration from the vasculature into the lungs. Finally, we treated Scnn1b-Tg mice and WT controls with anti-IL-5 antibody to deplete eosinophils from the lungs and evaluated effects on lung morphology.

\section{MATERIALS AND METHODS}

\section{Experimental animals}

All animal studies were approved by the Regierungspräsidium Karlsruhe, Germany or were in accordance with the Animal (Scientific Procedures) Act 1986 and current guidelines approved by the Ethical Review Committee of Queen's University Belfast (Belfast, UK). Scnn1b-Tg mice were studied on a C57BL/6N background as previously described (21). Scnn1b-Tg mice were inter-crossed with //1r1 1- mice on the C57BL/6 background (Jackson Laboratories, Bar Harbor, ME, USA) to generate Scnn1b$\mathrm{Tg} / \| 1 \mathrm{r} 1^{-1}, \mathrm{Scnn} 1 b-\mathrm{Tg}, / 11 r 1^{--}$and WT mice in the second generation and all analyses were performed on littermates. Offspring were genotyped as previously described $(6,22)$ and mice were studied at 3 , $8,10,12$ and 14 days of age. All animals were housed in specific pathogen free animal facilities and had free access to chow and water. 


\section{Eosinophil depletion}

Mice were treated by subcutaneous injections of $100 \mu \mathrm{g}$ of either anti-IL-5 antibody (TRFK5, BioXCell, $\mathrm{NH}$, USA) or an isotype control antibody (TNP6A7, BioXCell, NH, USA) at the age of 3, 6, 9 and 12 days after birth. At the age of 14 days, mice were killed by overdose of pentobarbital, BAL fluid was collected and lungs were inflated and fixed in formalin for assessment of structural lung damage as described below.

\section{Histology and airway morphology}

Murine lung tissue was fixed in formalin and embedded in paraffin, sections were cut at $5 \mu \mathrm{m}$ and stained with Alcian blue periodic acid-Schiff (AB-PAS) and with hematoxylin and eosin (H \& E) as described previously (9). Airway mucus content was assessed in the left proximal main axial airway by determining the volume of AB-PAS positive material per surface area $\left(\mathrm{nl} / \mathrm{mm}^{2}\right)$. For assessment of structural lung damage, right lungs were inflated to $25 \mathrm{~cm}$ of fixative pressure and mean linear intercepts (MLI) as a measurement of distal airspace enlargement and the destructive index (DI) as a measurement of alveolar wall destruction were evaluated as previously described $(6,23)$.

\section{Flow cytometry}

Multiparameter flow cytometry was performed using an LSRFortessa flow cytometer (BD Biosciences, Heidelberg, Germany). Single cell suspensions were obtained from whole lung and surface stained with fluorescent antibodies to delineate cell populations and surface expression of ICAM-1 and annexin V. Flow cytometry was performed immediately after cellular staining with exclusion of nonviable cells and doublets, and data were analyzed with FlowJo software (v10; TreeStar, Ashland, OR) as previously described (12). Additional details are provided in the online supplement.

\section{Real-time RT-PCR}

Semi-quantitative real time RT-PCR was performed on an Applied Biosystems 7500 Real Time PCR 
System using TaqMan Universal PCR master mix and inventoried TaqMan gene expression assays for II5 (Mm00439646_m1), II13 (Mm00434204_m1), CCl11 (Mm00441238_m1), and Ccl24 (Mm00444701_m1) (Applied Biosystems, Darmstadt, Germany). Relative fold change of target gene expression was determined by normalization to expression of the reference gene Actb (Mm00607939_s1).

\section{BAL cell counts and eosinophil granule protein measurement}

Mice were deeply anesthetized by means of intraperitoneal injection of $120 \mathrm{mg} / \mathrm{kg}$ ketamine and 16 mg/kg xylazine (Sigma-Aldrich, Taufkirchen, Germany) and exsanguinated. BAL and differential cell counts were performed as previously described (9) and detailed in the online supplement. Concentrations of the eosinophil granule proteins eosinophil cationic protein (ECP), major basic protein (MBP), and eosinophil peroxidase (EPO) and) in BAL fluid were quantified by ELISA (Biomatik, Cambridge, Canada).

\section{Statistics}

All data were analyzed using GraphPad Prism 5.0 (GraphPad Software Inc., San Diego, CA) and are reported as mean \pm SEM. Statistical analyses were performed using Student's t-test, Mann- Whitney Rank Sum test, one-way ANOVA, Kruskal-Wallis test or Pearson correlation coefficient as appropriate and $P<0.05$ was accepted to indicate statistical significance.

\section{RESULTS}

\section{Lack of IL-1R reduces spontaneous eosinophilic airway inflammation in juvenile Scnn1b-Tg mice}

To determine if IL-1R signaling contributes to the development of spontaneous airway inflammation in juvenile Scnn1b-Tg mice we compared inflammatory cell counts in BAL fluid collected from WT, $\| 1 r 1^{-/}$, Scnn $1 b$-Tg and Scnn $1 b-\mathrm{Tg} / \| 1 \mathrm{rr}^{-/}$mice at 8, 10, 12 and 14 days of age (Figure 1A-D). Consistent with previous studies $(6,9)$, juvenile $S c n n 1 b$-Tg mice presented with an increase in BAL total 
inflammatory cell counts compared to WT littermates (Figure 1A) associated with spontaneous neutrophilic as well as eosinophilic airway inflammation (Figure $1 \mathrm{C}$ and D). Lack of IL-1R had no effect on the number of total cells or macrophages in the BAL fluid of juvenile Scnn1b-Tg mice (Figure A and B), but reduced airway neutrophils as previously shown in studies of neonatal and adult Scnn1b-Tg mice (17) (Figure 1C). In addition, lack of IL-1R largely reduced the development of airway eosinophilia in juvenile Scnn1b-Tg mice. Specifically, eosinophil counts in BAL were significantly reduced in Scnn1b$\mathrm{Tg} / \mathrm{ll} 1 \mathrm{r} \mathrm{1}^{-}$mice compared to Scnn1b-Tg mice of the same age from 10 days of age onward (Figure 1D). These results demonstrate that IL-1R signaling contributes to the development of spontaneous eosinophilic airway inflammation in juvenile Scnn1b-Tg mice.

Lack of IL-1R delays, but does not prevent, the onset of type 2 airway inflammation in juvenile

\section{Scnn1b-Tg mice}

Our previous studies demonstrated that spontaneous airway eosinophilia is associated with transient type 2 airway inflammation in juvenile $\operatorname{Scnn} 1 b$ - Tg mice $(9,24)$. To examine the role of IL-1R signaling in this age-dependent type 2 inflammation associated with muco-obstructive lung disease, we next performed longitudinal measurements of transcript levels of the key type 2 cytokines $/ / 13$ and $/ / 5$, and eosinophil chemoattractants $C c / 11$ and $C c / 24$, (Figure 2A-D) in lung tissues from neonatal to juvenile $\mathrm{WT}, \| 1 \mathrm{r} 1^{-}$, Scnn $1 b$-Tg and Scnn1b-Tg//I1r1\% mice (i.e. at 3, 8, 10, 12 and 14 days of age). Consistent with previous studies, we observed no difference in expression of these type 2 cytokines between Scnn1b-Tg mice and WT littermates of neonatal age (9). However, transcript levels were increased in juvenile Scnn $1 b$-Tg mice peaking around day 8 to 10 before beginning to wane (Figure $2 A-D$ ). Scnn $1 b$ $\mathrm{Tg} / / 11 \mathrm{r}^{-/}$mice showed a significant reduction in the expression of $/ 113$ and $/ 15$ transcripts at day 8 compared to their Scnn1b-Tg littermates of the same age (Figure 2A and B). Similarly, a trend toward reduction in expression of the eosinophil chemoattractants $C c / 11$ and $C c / 24$ was observed at 8 days of age (Figure $2 \mathrm{C}$ and $\mathrm{D}$ ). These results suggest that IL-1R may contribute to the initiation of type 2 inflammation in this model. However, at later time points, lack of IL-1R had no effect on transcript 
levels of any of these key type 2 cytokines demonstrating that IL-1R signaling is not essential for the upregulation of type 2 cytokines in juvenile $S c n n 1 b$-Tg mice (Figure 2A-D). When viewed in combination with BAL eosinophil counts (Figure 1D) these data show that IL-1R is implicated in eosinophilic airway inflammation in juvenile Scnn $1 b$-Tg mice independent of type 2 inflammation.

\section{Lack of IL-1R does not prevent activation of airway eosinophils in juvenile Scnn1b-Tg mice}

Previous studies showed a shift in the eosinophil phenotype during allergic inflammation to a Siglec $\mathrm{F}^{\text {high }} / \mathrm{CD} 11 \mathrm{c}^{\text {low }}$ phenotype that is associated with enhanced recruitment of eosinophils to the airways (25). Because we observed a sustained decrease in airway eosinophil counts, but not type 2 cytokines in lungs from juvenile Scnn $1 b$ - Tg/IIIr $1^{-/}$mice, we therefore examined the effects of IL-1R knockout on this eosinophil phenotype in lungs from WT, $\| 1 r 1^{-1}$, Scnn $1 b$-Tg and Scnn $1 b-\mathrm{Tg} / \| 1 \mathrm{r} 1^{-/-}$mice by flow cytometry (Figure $3 \mathrm{~A}-\mathrm{C}$ ). In these studies, we compared eosinophil activation, as determined from the Siglec $\mathrm{F}^{\text {high }} / \mathrm{CD} 11 \mathrm{c}^{\text {low }}$ phenotype, at 8 days of age when transcript levels of type 2 cytokines were still in the normal range observed in WT mice, and at 12 days of age when type 2 cytokine transcripts were increased to similar levels in Scnn1b-Tg/IIr1 $1 \%$ compared to Scnn $1 b$-Tg mice (Figure 2A-D). At both time points Scnn1b-Tg mice had a significantly higher proportion of Siglec Figh $/ \mathrm{CD} 11 c^{\text {low }}$ eosinophils compared to WT littermates (Figure 3B and C). In Scnn1b-Tg/IIr $11^{-/}$mice the proportion of Siglec $\mathrm{F}^{\text {high }} / \mathrm{CD} 11 \mathrm{c}^{\text {low }}$ airway eosinophils was reduced compared to Scnn $1 b$-Tg mice at 8 days, but increased to similar levels at 12 days of age. (Figure 3A-C). As an independent measure of eosinophil activation, we determined levels of secreted eosinophil granule proteins ECP, MBP and EPO in BAL fluid from 14 day old WT, $\| 11 r^{-/}$, Scnn $1 b$-Tg and Scnn $1 b-\mathrm{Tg} / \| 1 \mathrm{rr}^{-/}$mice. Consistent with low-grade airway eosinophilia in this age group (Figure 1D) $(9,11,12)$, all three secreted eosinophil granule proteins were detected at low levels in juvenile WT mice (Figure E1). In Scnn1b-Tg mice, ECP and MBP remained unchanged, whereas EPO was significantly increased compared to WT controls (Figure E1). A similar pattern was observed in BAL fluid of Scnn $1 b$ - Tg/IIIr $1^{-/-}$mice, where reduced levels of eosinophils were associated with reduced levels of EPO compared to Scnn1b-Tg mice (Figure E1C). Taken together, 
these results suggest that IL-1R signaling is not essential for eosinophil activation that is associated with type 2 airway inflammation in juvenile Scnn1b-Tg mice.

Lack of IL-1R reduces endothelial ICAM-1 expression and eosinophil recruitment to the lungs in juvenile mice

It was previously shown that IL-1R signaling activates endothelial cells and promotes leukocyte transmigration by inducing the expression of the surface integrin ICAM-1 $(26,27)$. To examine the potential role of IL-1R in recruitment of eosinophils from the circulation into the lung, we first determined eosinophil numbers by flow cytometry in whole lung tissue from WT, $\| 111^{-1-}$, Scnn $1 b-\mathrm{Tg}$ and Scnn $1 \mathrm{~b}$-Tg/IIIr1 ${ }^{--}$mice at 3, 8, 10 and 12 days of age (Figure $4 \mathrm{~A}$ ). Similar to BAL fluid, whole lung eosinophil counts were increased in Scnn1b-Tg mice compared to WT mice at 10 and 12 days of age. Lack of IL-1R reduced eosinophil numbers in lung tissue of both WT and Scnn1b-Tg mice with significant reductions at 8 and 10 days in WT and 10 and 12 days in Scnn $1 b$-Tg mice (Figure 4A). Next, we examined expression levels of ICAM-1 on endothelial cells by flow cytometry in WT, II1r1 ${ }^{-1}$, Scnn $1 b$ $\mathrm{Tg}$ and Scnn $1 b-\mathrm{Tg} / / 11 \mathrm{r}^{-/}$mice at 14 days of age (Figure 4B). Endothelial ICAM-1 expression was unchanged in Scnn1b-Tg compared to WT mice. However, expression of ICAM-1 was significantly reduced in both $/ / 1 r^{-/-}$and Scnn1b-Tg/IIIr1 $1^{--}$mice (Figure 4B). To examine if differences in apoptosis may be involved in reduced eosinophil counts in Scnn1b-Tg/IIr $1^{-/-}$compared to Scnn1b-Tg mice, we examined annexin $V$ surface expression as a marker of apoptotic cell death on airway eosinophils from 14 day old WT, $\| 1 r 1^{-/}$, Scnn1b-Tg and Scnn1b-Tg/II1r1 $1^{-/}$mice (Figure 4C). The percentage of apoptotic cells was $\sim 21 \%$ increased in Scnn1b-Tg compared to WT mice but remained unchanged in Scnn1b$\mathrm{Tg} / / 1 \mathrm{r} 1^{-/-}$compared to Scnn $1 b$-Tg mice demonstrating that eosinophil apoptosis was not affected by the lack of IL-1R (Figure 4C). Taken together, these data show that lack of IL-1R reduced endothelial ICAM-1 expression and total lung eosinophil counts, but did not affect apoptotic cell death, in WT and Scnn1b-Tg mice. These data suggest that IL-1R signaling is implicated in eosinophil migration from the blood into the lung tissue and that abrogation of this function contributes to the reduction of 
eosinophilia observed in lung tissue and BAL from Scnn $1 b$ - Tg/IIr $1^{-/}$compared to Scnn $1 b$-Tg mice.

\section{Lack of IL-1R and eosinophil depletion reduces structural lung damage in juvenile Scnn1b-Tg mice}

We previously demonstrated emphysema-like structural damage of distal airspaces in juvenile Scnn1b-Tg mice, however, the relationship between airway eosinophilia and early lung damage has not been studied $(7,9)$. We, therefore, compared MLI and DI in WT, $/ 11 \mathrm{rI}^{-/}, \mathrm{Scnn} 1 \mathrm{~b}$-Tg and Scnn1b$\mathrm{Tg} / \mathrm{II} 1 \mathrm{r}^{--}$mice at 14 days of age (Figure $\left.5 \mathrm{~A}-\mathrm{C}\right)$. As expected from previous studies $(9,28), \mathrm{MLI}$ and DI were increased in Scnn1b-Tg compared to WT mice. No difference was observed in MLI and DI between WT and $\| 1 r 1^{-}$mice. However, in Scnn $1 b-\mathrm{Tg} / \| 1 \mathrm{r} 1^{-}$mice $\mathrm{MLI}$ and DI were significantly reduced compared to Scnn1b-Tg mice (Figure $5 \mathrm{~A}-\mathrm{C}$ ). To determine the specific role of eosinophils in structural lung damage more directly, we next performed eosinophil depletion experiments. We treated neonatal Scnn1b-Tg mice and WT controls with anti-IL5 antibody or isotype control and examined effects on emphysema-like structural lung damage. Anti-IL5 treatment specifically depleted eosinophils without reducing neutrophil or macrophage counts in BAL fluid of juvenile Scnn $1 b$ - Tg mice (Figure 6A-D). Eosinophil depletion was associated with a significant decrease in MLI in Scnn1b-Tg mice (Figure 6F). In addition, we found a direct correlation between BAL eosinophil counts and $\mathrm{MLI}$ in Scnn1b-Tg mice (Figure 6G). These results support that activated airway eosinophils contribute to the development of structural lung damage in early muco-obstructive lung disease in juvenile Scnn1b-Tg mice.

\section{DISCUSSION}

This study demonstrates for the first time that impaired airway mucus clearance triggers spontaneous eosinophilic airway inflammation in juvenile mice that is, in part, mediated by IL-1R signaling independent of type 2 cytokine expression (Figure 1 and 2). We show that lack of IL-1R signaling had no effect on eosinophil activation or apoptosis in the airways, but is associated with reduced expression of the integrin ICAM-1 on endothelial cells and may thereby contribute to reduced migration of eosinophils from the circulation into the lung tissue (Figure 3 and 4). Finally, reduction of 
airway eosinophilia in juvenile Scnn1b-Tg mice, either by genetic deletion of IL-1R or by eosinophil depletion, was associated with a decrease in emphysema-like distal airspace enlargement suggesting that activated eosinophils contribute to early structural lung damage (Figure 5 and 6 ). Collectively our results provide novel insights into the role of IL-1R signaling in the in vivo pathogenesis of airway eosinophilia in muco-obstructive lung disease.

Our results show that the development of spontaneous eosinophilic airway inflammation characteristic of juvenile Scnn1b-Tg mice (9-11) requires intact IL-1R signaling in addition to chemotactic factors released in type 2 airway inflammation (Figure 1). We speculate that the continued presence of type 2 inflammatory cytokines despite attenuated airway eosinophilia in juvenile Scnn $1 b$ - Tg/II $1 r 1^{-/}$mice may be driven by release of interleukin-13 (IL-13) from a spectrum of innate and adaptive immune cells that are activated by inhaled allergens and other irritants retained in mucostatic airways of juvenile Scnn1b-Tg mice. This hypothesis is supported by a recent study demonstrating that IL-13 levels were increased in airway epithelial cells, macrophages, type 2 innate lymphoid cells (ILC2), and T helper type 2 (TH2) cells in juvenile Scnn1b-Tg mice vs. WT mice at baseline, and that IL-13 production by these cell types is further increased upon allergen challenge (12). Whilst IL-1R was not essential for the upregulation of type 2 cytokines in Scnn1b-Tg mice, our longitudinal measurements in neonatal and juvenile mice indicate that IL-1R signaling may contribute to the initiation of this inflammatory response (Figure 2). This is in line with previously published data showing that IL-1R is implicated in the initiation of type 2 inflammation in a HDM-induced model of allergic lung disease (16).

Lack of IL-1R reduced eosinophils not only in the airways, but also in the whole lung (Fig. 4A) suggesting that trans-endothelial migration of eosinophils from the blood into the lung tissue may be a potential mechanism for the observed reduction in airway eosinophilia in juvenile $S c n n 1 b-\mathrm{Tg} / I 1 \mathrm{r} 1^{-1}$ mice. In this context, interleukin-1 (IL-1) is a well-known activator of the vascular endothelium modulating the adhesive properties of endothelial cells via adhesion molecules such as ICAM-1 that are essential for 
the regulation of leukocyte migration into tissues during inflammation (29-31). We observed a small but significant downregulation of ICAM-1 on lung endothelial cells from WT ( 22\%) and Scnn1b-Tg ( 12\%) mice lacking IL-1R (Figure 4B). ICAM-1, a major endothelial adhesion molecule has previously been shown to be induced by IL-1 and contributed to eosinophil adhesion to the vascular endothelium $(32,33)$. Of note, previous studies have shown that even small changes in ICAM-1 expression can result in physiologically relevant changes in leukocyte adhesion (34). The downregulation of ICAM-1 in IL-1R deficient mice in our study may therefore lead to reduced transendothelial migration of eosinophils into the lung tissue, thereby reducing the pool of tissue eosinophils available to migrate into the airways of juvenile Scnn1b-Tg mice along the chemoattractant gradient set by type 2 cytokines and eosinophil chemoattractants. Of note, this notion is supported by a previous study showing that knockout of IL-1R on structural lung cells, but not inflammatory cells, was required in order to demonstrate a reduction in airway eosinophilia in mice with HDM-induced asthma (16). Collectively, these data suggest IL-1R and/or ICAM-1 as potential therapeutic targets to inhibit airway eosinophilia in allergen-induced asthma and other muco-obstructive lung diseases.

Finally, we show that lack of IL-1R reduced emphysema-like lung damage, as determined from measurements of $\mathrm{MLI}$ and $\mathrm{DI}$ in juvenile $S \mathrm{Cnn} 1 \mathrm{~b}-\mathrm{Tg} / \mathrm{II} 1 \mathrm{r} 1^{-/-}$mice (Figure $5 \mathrm{~A}-\mathrm{C}$ ). In previous studies we demonstrated that neutrophil elastase (NE), macrophage elastase (matrix metalloproteinase 12 [MMP-12]) and cathepsin S released from activated neutrophils and macrophages in mucostatic airways, are major contributors to structural lung damage in Scnn1b-Tg mice $(28,35,36)$. While airway neutrophils were also reduced in $S c n n 1 b-\mathrm{Tg} / \mathrm{Il} 1 \mathrm{r}^{-/}$mice (Figure $1 \mathrm{C}$ ), it is important to note that $\mathrm{Scnn} 1 \mathrm{~b}-\mathrm{Tg} / \mathrm{NE}^{-/-}$presented with residual emphysema suggesting that other factors may contribute to emphysema formation in this model. However, lack of IL-1R had no effect on macrophages (Figure 1B) constituting the primary source of MMP-12 in the airways making it unlikely that the striking reduction in emphysema observed in juvenile Scnn $1 b-\mathrm{Tg} / / 1 \mathrm{rr} 1^{-/-}$mice in this study was determined by alterations in macrophage function. We therefore depleted eosinophils to assess their specific role in structural lung damage in juvenile Scnn1b-Tg mice. Eosinophil depletion by treatment with anti-IL-5 antibody 
had no effect on neutrophil or macrophage counts in BAL fluid, but resulted in a significant decrease in $\mathrm{MLI}$ and more preserved architecture of the distal airspaces in Scnn1b-Tg mice (Figure 6A-F). Of note, the effect of eosinophil depletion on elevated MLI was less complete than the effect of genetic deletion of IL-1R that resulted in a reduction of airway eosinophils and neutrophils, and normalized MLI almost completely in juvenile Scnn1b-Tg mice (Figure 1 and Figure 5). A role for eosinophils in the development of early structural lung damage in Scnn1b-Tg mice is also supported by the direct correlation between airway eosinophils and distal airspace enlargement in juvenile Scnn1b-Tg mice (Figure $6 \mathrm{G}$ ). In this context, we found that EPO secreted by activated eosinophils was significantly increased in the airways of juvenile Scnn1b-Tg mice. As EPO was previously shown to be cytotoxic to a variety of cell types including the airway epithelium $(37,38)$ and to be negatively correlated with $\mathrm{FEV}_{1}$ in asthma patients (39), we speculate this eosinophil granule protein may be a potential candidate for eosinophil-mediated structural lung damage in Scnn1b-Tg mice (Figure E1). Taken together, our results support that eosinophils, in addition to neutrophils, contribute to the development of early structural lung damage in this model of muco-obstructive lung disease.

In summary, we show that IL-1R signaling contributes to spontaneous airway eosinophilia in juvenile Scnn1b-Tg mice featuring muco-obstructive lung disease. This role of IL-1R signaling was independent of type 2 cytokine expression and possibly mediated via the surface integrin ICAM-1 on vascular endothelial cells and concomitant activation of eosinophil migration from the circulation into the lung tissue. Additionally, we demonstrate that inhibition of airway eosinophilia in juvenile Scnn1b-Tg mice by genetic deletion of IL-1R or eosinophil depletion was associated with reduced structural lung damage. Collectively, our results support an important role of IL-1R signaling in the in vivo pathogenesis of airway eosinophilia and neutrophilia and suggest IL-1R as a potential novel therapeutic target (40) to inhibit this hallmark phenotype in muco-obstructive lung diseases. 


\section{REFERENCES}

1. George L, Brightling CE. Eosinophilic airway inflammation: role in asthma and chronic obstructive pulmonary disease. Ther Adv Chronic Dis 2016;7:34-51.

2. Eltboli O, Brightling CE. Eosinophils as diagnostic tools in chronic lung disease. Expert Rev Respir Med $2013 ; 7: 33-42$.

3. Possa SS, Leick EA, Prado CM, Martins MA, Tibério IFLC. Eosinophilic inflammation in allergic asthma. Front Pharmacol 2013;4:46.

4. Lams BE, Sousa AR, Rees PJ, Lee TH. Subepithelial immunopathology of the large airways in smokers with and without chronic obstructive pulmonary disease. Eur Respir J 2000;15:512- 6.

5. Balzano G, Stefanelli F, lorio C, De Felice A, Melillo EM, Martucci M, Melillo G. Eosinophilic Inflammation in Stable Chronic Obstructive Pulmonary Disease. Am J Respir Crit Care Med 1999;160:1486-1492.

6. Mall M, Grubb BR, Harkema JR, O’Neal WK, Boucher RC, Neal WKO. Increased airway epithelial Na+ absorption produces cystic fibrosis-like lung disease in mice. Nat Med 2004;10:487-493.

7. Wielputz MO, Eichinger M, Zhou Z, Leotta K, Hirtz S, Bartling SH, Semmler W, Kauczor H-U, Puderbach M, Mall M a. In vivo monitoring of cystic fibrosis-like lung disease in mice by volumetric computed tomography. Eur Respir J 2011;38:1060-1070.

8. Zhou Z, Duerr J, Johannesson B, Schubert SC, Treis D, Harm M, Graeber SY, Dalpke A, Schultz C, Mall $\mathrm{M}$ a. The ENaC-overexpressing mouse as a model of cystic fibrosis lung disease. J Cyst Fibros 2011;10 Suppl 2:S172-82.

9. Mall MA, Harkema JR, Trojanek JB, Treis D, Livraghi A, Schubert S, Zhou Z, Kreda SM, Tilley SL, Hudson EJ, Neal WKO, Boucher RC. Development of Chronic Bronchitis and Emphysema in b Epithelial Na 1 Channel - Overexpressing Mice. Am J Respir Crit Care Med 2008;177:730-742.

10. Zhou-Suckow Z, Duerr J, Hagner M, Mall MA. Airway mucus, inflammation and remodeling: emerging links in the pathogenesis of chronic lung diseases. Cell Tissue Res 2017; 367(3):537- 550

11. Livraghi A, Grubb BR, Hudson EJ, Wilkinson KJ, Sheehan JK, Mall M a, O’Neal WK, Boucher RC, 
Randell SH. Airway and lung pathology due to mucosal surface dehydration in \{beta\}- epithelial Na+ channel overexpressing mice: role of TNF-\{alpha\} and IL-4R\{alpha\} signaling, influence of neonatal development, and limited efficacy of glucocorticoid treatment. J Immunol 2009;182:4357-67.

12. Fritzsching B, Hagner M, Dai L, Christochowitz S, Agrawal R, van Bodegom C, Schmidt S, Schatterny J, Hirtz S, Brown R, Goritzka M, Duerr J, Zhou-Suckow Z, Mall MA. Impaired mucus clearance exacerbates allergen-induced type 2 airway inflammation in juvenile mice. J Allergy Clin Immunol 2017;140:190-203.

13. Wang C-C, Fu C-L, Yang Y-H, Lo Y-C, Wang L-C, Chuang Y-H, Chang D-M, Chiang B-L. Adenovirus expressing interleukin-1 receptor antagonist alleviates allergic airway inflammation in a murine model of asthma. Gene Ther 2006;13:1414-1421.

14. Broide DH, Campbell K, Gifford T, Sriramarao P. Inhibition of eosinophilic inflammation in allergen challenged, IL-1 receptor type 1-deficient mice is associated with reduced eosinophil rolling and adhesion on vascular endothelium. Blood 2000;95:263-9.

15. Nakae S, Komiyama Y, Yokoyama H, Nambu A, Umeda M, Iwase M, Homma I, Sudo K, Horai R, Asano M, Iwakura Y. IL-1 is required for allergen-specific Th2 cell activation and the development of airway hypersensitivity response. Int Immunol 2003;15:483-90.

16. Willart MAM, Deswarte K, Pouliot P, Braun H, Beyaert R, Lambrecht BN, Hammad H. Interleukin-1 $\alpha$ controls allergic sensitization to inhaled house dust mite via the epithelial release of GM-CSF and IL33. J Exp Med 2012;209:1505-17.

17. Fritzsching B, Zhou-Suckow Z, Trojanek JB, Schubert SC, Schatterny J, Hirtz S, Agrawal R, Muley T, Kahn N, Sticht C, Gunkel N, Welte T, Randell SH, Länger F, Schnabel P, Herth FJF, Mall MA. Hypoxic Epithelial Necrosis Triggers Neutrophilic Inflammation via IL-1 Receptor Signaling in Cystic Fibrosis Lung Disease. Am J Respir Crit Care Med 2015;191:902-913.

18. Chen C-J, Kono H, Golenbock D, Reed G, Akira S, Rock KL. Identification of a key pathway required for the sterile inflammatory response triggered by dying cells. Nat Med 2007;13:851-856.

19. Montgomery ST, Mall MA, Kicic A, Stick SM, AREST CF. Hypoxia and sterile inflammation in cystic 
fibrosis airways: mechanisms and potential therapies. Eur Respir J 2017;49:1600903.

20. Balazs A, Mall MA. Mucus obstruction and inflammation in early cystic fibrosis lung disease: emerging role of the IL-1 signaling pathway. Pediatr Pulmonol in press.

21. Johannesson B, Hirtz S, Schatterny J, Schultz C, Mall M a. CFTR regulates early pathogenesis of

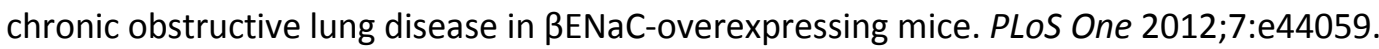

22. Glaccum MB, Stocking KL, Charrier K, Smith JL, Willis CR, Maliszewski C, Livingston DJ, Peschon JJ, Morrissey PJ. Phenotypic and functional characterization of mice that lack the type I receptor for IL1. J Immunol 1997;159:3364-71.

23. Saetta M, Shiner RJ, Angus GE, Kim WD, Wang NS, King M, Ghezzo H, Cosio MG. Destructive index: a measurement of lung parenchymal destruction in smokers. Am Rev Respir Dis 1985;131:764-9.

24. Zhou Z, Treis D, Schubert SC, Harm M, Schatterny J, Hirtz S, Duerr J, Boucher RC, Mall M a. Preventive but not late amiloride therapy reduces morbidity and mortality of lung disease in betaENaC overexpressing mice. Am J Respir Crit Care Med 2008;178:1245-56.

25. Abdala Valencia H, Loffredo LF, Misharin A V., Berdnikovs S. Phenotypic plasticity and targeting of Siglec- $F^{\text {high }}$ CD11c ${ }^{\text {low }}$ eosinophils to the airway in a murine model of asthma. Allergy 2016;71:267271.

26. Majewska E, Paleolog E, Baj Z, Kralisz U, Feldmann M, Tchórzewski H. Role of tyrosine kinase enzymes in TNF-alpha and IL-1 induced expression of ICAM-1 and VCAM-1 on human umbilical vein endothelial cells. Scand J Immunol 1997;45:385-92.

27. Rahman A, Fazal F. Hug tightly and say goodbye: role of endothelial ICAM-1 in leukocyte transmigration. Antioxid Redox Signal 2009;11:823-39.

28. Gehrig S, Duerr J, Weitnauer M, Wagner CJ, Graeber SY, Schatterny J, Hirtz S, Belaaouaj A, Dalpke AH, Schultz C, Mall M a. Lack of neutrophil elastase reduces inflammation, mucus hypersecretion and emphysema, but not mucus obstruction, in mice with CF-like lung disease. Am J Respir Crit Care Med 2014;189:1082-1092.

29. Bevilacqua MP, Pober JS, Wheeler ME, Cotran RS, Gimbrone MA, Jr. Interleukin-1 activation of 
vascular endothelium. Effects on procoagulant activity and leukocyte adhesion. 1985;121:.

30. Malik AB, Lo SK. Vascular endothelial adhesion molecules and tissue inflammation. Pharmacol Rev $1996 ; 48: 213-29$.

31. Muller WA. Mechanisms of leukocyte transendothelial migration. Annu Rev Pathol 2011;6:323-44.

32. Jia GQ, Gonzalo JA, Hidalgo A, Wagner D, Cybulsky M, Gutierrez-Ramos JC. Selective eosinophil transendothelial migration triggered by eotaxin via modulation of Mac-1/ICAM-1 and VLA-4/VCAM1 interactions. Int Immunol 1999;11:1-10.

33. Myers CL, Wertheimer SJ, Schembri-King J, Parks T, Wallace RW. Induction of ICAM-1 by TNF- alpha, IL-1 beta, and LPS in human endothelial cells after downregulation of PKC. Am J Physiol Physiol 1992;263:C767-C772.

34. Salkind AR, Nichols JE, Roberts NJ. Suppressed expression of ICAM-1 and LFA-1 and abrogation of leukocyte collaboration after exposure of human mononuclear leukocytes to respiratory syncytial virus in vitro. Comparison with exposure to influenza virus. J Clin Invest 1991;88:505-511.

35. Small DM, Brown RR, Doherty DF, Abladey A, Zhou-Suckow Z, Delaney RJ, Kerrigan L, Dougan CM, Borensztajn KS, Holsinger L, Booth R, Scott CJ, López-Campos G, Elborn JS, Mall MA, Weldon S, Taggart CC. Targeting of cathepsin S reduces cystic fibrosis-like lung disease. Eur Respir J 2019;53:1801523.

36. Trojanek JB, Cobos-Correa A, Diemer S, Kormann M, Schubert SC, Zhou-Suckow Z, Agrawal R, Duerr J, Wagner CJ, Schatterny J, Hirtz S, Sommerburg O, Hartl D, Schultz C, Mall MA. Airway Mucus Obstruction Triggers Macrophage Activation and Matrix Metalloproteinase 12- Dependent Emphysema. Am J Respir Cell Mol Biol 2014;51:709-720.

37. Acharya KR, Ackerman SJ. Eosinophil granule proteins: form and function. J Biol Chem 2014;289:17406-15.

38. Kato M, Ishioka T, Kita H, Kozawa K, Hayashi Y, Kimura H. Eosinophil Granular Proteins Damage Bronchial Epithelial Cells Infected with Respiratory Syncytial Virus. Int Arch Allergy Immunol 2012;158:11-18. 
39. Sanz ML, Parra A, Prieto I, Diéguez I, Oehling AK. Serum eosinophil peroxidase (EPO) levels in asthmatic patients. Allergy 1997;52:417-422.

40. Dinarello CA, Simon A, Meer JWM van der. Treating inflammation by blocking interleukin-1 in a broad spectrum of diseases. Nat Rev Drug Discov 2012;11:633. 


\section{FIGURE LEGENDS}

Figure 1. Lack of IL-1R reduces spontaneous eosinophilic airway inflammation in juvenile Scnn1b-Tg mice. (A-D) Total cell (A), macrophage (B), neutrophil (C) and eosinophil (D) counts in bronchoalveolar lavage (BAL) fluid from juvenile wild-type (WT), II1r1 ${ }^{-1-}$, Scnn1b-Tg and double mutant Scnn1b-Tg/IIr1 1- mice at indicated time points during development ( 8 days, 10 days, 12 days and 14 days of age) as determined from May-Grünwald Giemsa stained cytospins. $n=5-28$ mice per group. ${ }^{*} P<0.05,{ }^{* *} P$ $<0.01,{ }^{* * *} P<0.001$ compared with WT. ${ }^{\dagger} P<0.05,{ }^{\ddagger} P<0.001$ compared with Scnn1b-Tg.

Figure 2. Lack of IL-1R delays, but does not prevent the onset of type 2 airway inflammation in juvenile Scnn1b-Tg mice. (A-D) Longitudinal measurements of transcript levels of $/ / 13$ (A), /l5 (B), Cc/11 (C) and $C c / 24$ (D) in lungs from juvenile wild-type (WT), $I / 1 r^{-\%}$, Scnn1b-Tg and double mutant Scnn $1 b$ $\mathrm{Tg} / / 1 \mathrm{r} 1^{-/-}$mice at indicated ages during postnatal development ( 3 days, 8 days, 10 days, 12 days and 14 days of age). $\mathrm{n}=4-8$ mice per group. ${ }^{*} P<0.05,{ }^{* *} P<0.01$ compared with $\mathrm{WT} .{ }^{\dagger} P<0.05,{ }^{\ddagger} P<0.001$ compared with Scnn1b-Tg.

Figure 3. Lack of IL-1R does not prevent activation of airway eosinophils in juvenile Scnn1b-Tg mice. (A) Example dot plots showing 20,000 events in lung tissues of Scnn1b-Tg and Scnn1b-Tg/II1r1\% mice at 8 days and 12 days of age showing activated eosinophil phenotype (SiglecF ${ }^{\text {high }} / C D 11 c^{\text {low }}$ ). (B-C) Percent of total activated lung eosinophils expressing the SiglecF $F^{\text {high }} / C D 11 c^{\text {low }}$ phenotype at 8 days (B) and 12 days $(C)$ of age. $n=5-18$ mice per group. ${ }^{*} P<0.01{ }^{* *} P<0.001$ compared with wild-type (WT). ${ }^{\dagger} P<0.05$ compared with Scnn1b-Tg.

Figure 4. Lack of IL-1R reduces endothelial ICAM-1 expression and eosinophil recruitment to the lungs of juvenile wild-type (WT) and Scnn1b-Tg mice. (A) Eosinophil counts in whole lung determined by flow cytometry in WT, $\| 1 r^{-1-}$, Scnn $1 b$-Tg and double mutant Scnn $1 b-\mathrm{Tg} / \| 1 \mathrm{r} \mathrm{1}^{- \text {- }}$ mice between 3 and 12 days of age. (B) ICAM-1 expression on endothelial cells from WT, $\| 1 r 1^{-1-}$, Scnn $1 b$-Tg and Scnn $1 b$ $\mathrm{Tg} / \mathrm{II} 1 \mathrm{rI}^{-/}$mice at 14 days of age determined by flow cytometry. (C) Percentage of apoptotic 
eosinophils in BAL fluid from WT, $\| 1 r^{-1}{ }^{-}$, Scnn1b-Tg and Scnn $1 b-\mathrm{Tg} / \| 1 \mathrm{rr}^{--}$mice at 14 days of age determined by annexin $\mathrm{V}$ expression. $\mathrm{n}=5-22$ mice per group. ${ }^{*} P<0.05,{ }^{* *} P<0.01,{ }^{* * *} P<0.001$ compared to WT. ${ }^{\dagger} P<0.05,{ }^{\ddagger} P<0.01$ compared with Scnn $1 b$-Tg.

Figure 5. Lack of IL-1R reduces structural lung damage in juvenile Scnn1b-Tg mice. (A) Representative

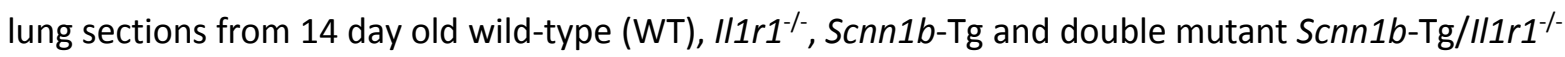
mice stained with hematoxylin and eosin (H \& E). Scale bar $=100 \mu \mathrm{m}$. (B) Mean linear intercept (MLI) and $(C)$ destructive index (DI) was accessed from $\mathrm{H}$ \& E stained lung sections. $n=5-7$ mice per group. ${ }^{*} P<0.001$ compared to WT. ${ }^{\dagger} P<0.05$ compared with Scnn $1 b$-Tg.

Figure 6. Eosinophil depletion reduces structural lung damage in Scnn1b-Tg mice. Wild-type (WT) and Scnn1b-Tg mice were treated with anti-IL-5 antibody or isotype control at the age of 3, 6, 9 and 12 days after birth and endpoint studies were performed at the age of14 days. (A-D) Total cell (A), macrophage (B), neutrophil (C) and eosinophil (D) counts in bronchoalveolar lavage (BAL). (E) Representative lung sections stained with hematoxylin and eosin (H \& E). Scale bar $=100 \mu \mathrm{m}$. (F) Mean linear intercept (MLI) was accessed from H \& E stained lung sections. (G) Relationship between BAL eosinophil counts and MLI in Scnn1b-Tg mice. $\mathrm{n}=7-14$ mice per group. ${ }^{*} P<0.001,{ }^{*} P<0.0001$ compared to $\mathrm{WT},{ }^{\dagger} P<0.05,{ }^{\ddagger} P<0.001$ compared with Scnn $1 b$-Tg. 
Figure 1
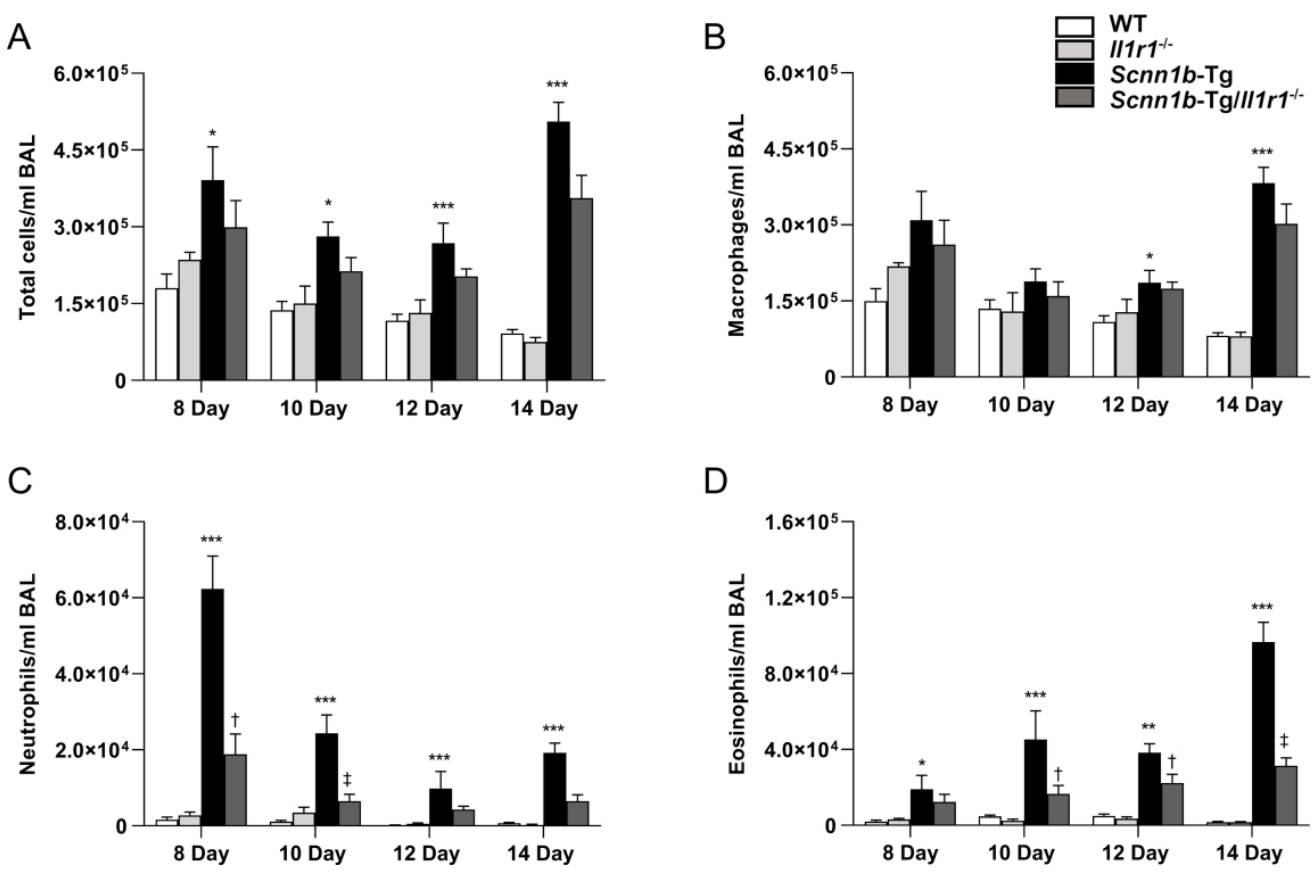

$148 \times 110 \mathrm{~mm}(600 \times 600 \mathrm{DPI})$ 
Figure 2

A

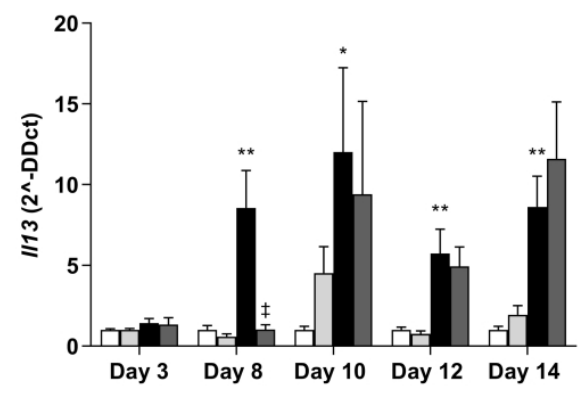

C

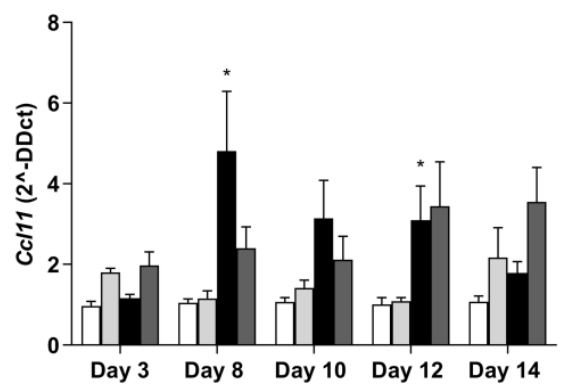

B

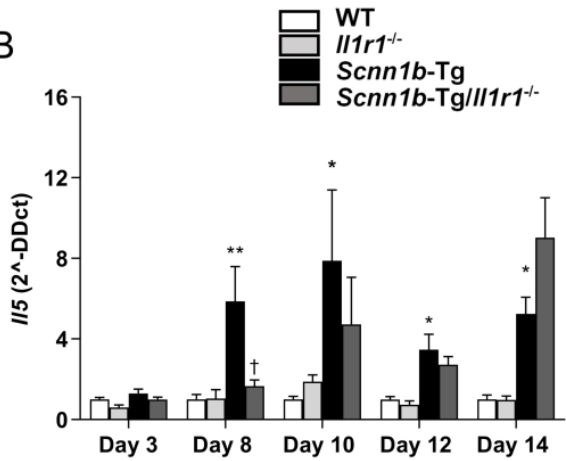

D

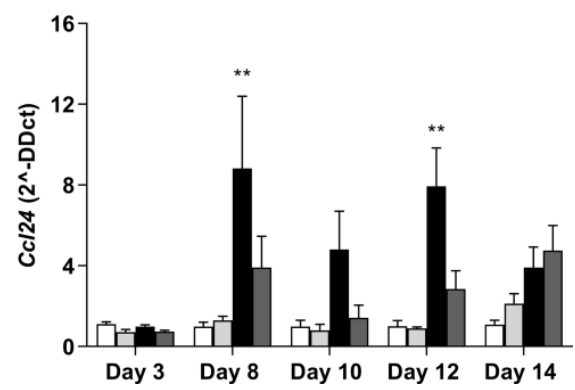

$148 \times 117 \mathrm{~mm}(600 \times 600 \mathrm{DPI})$ 
Figure 3
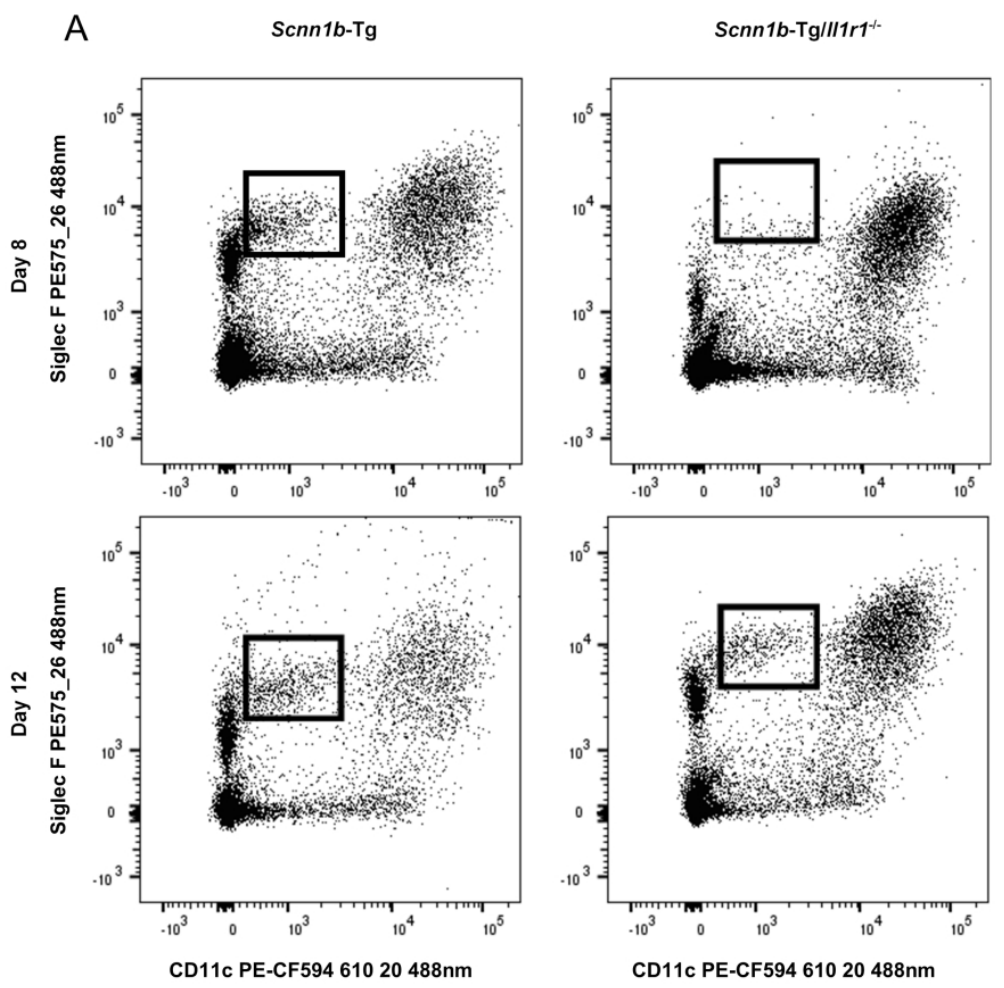

B
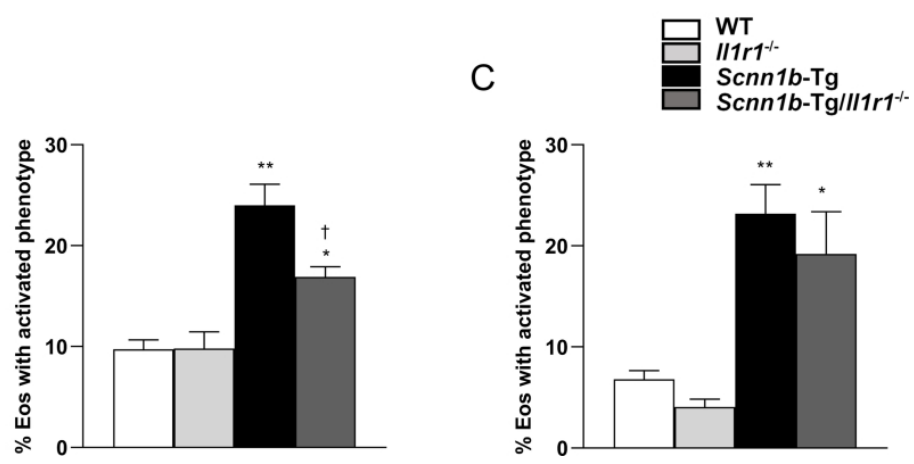

$110 \times 161 \mathrm{~mm}(600 \times 600 \mathrm{DPI})$ 
Figure 4

A

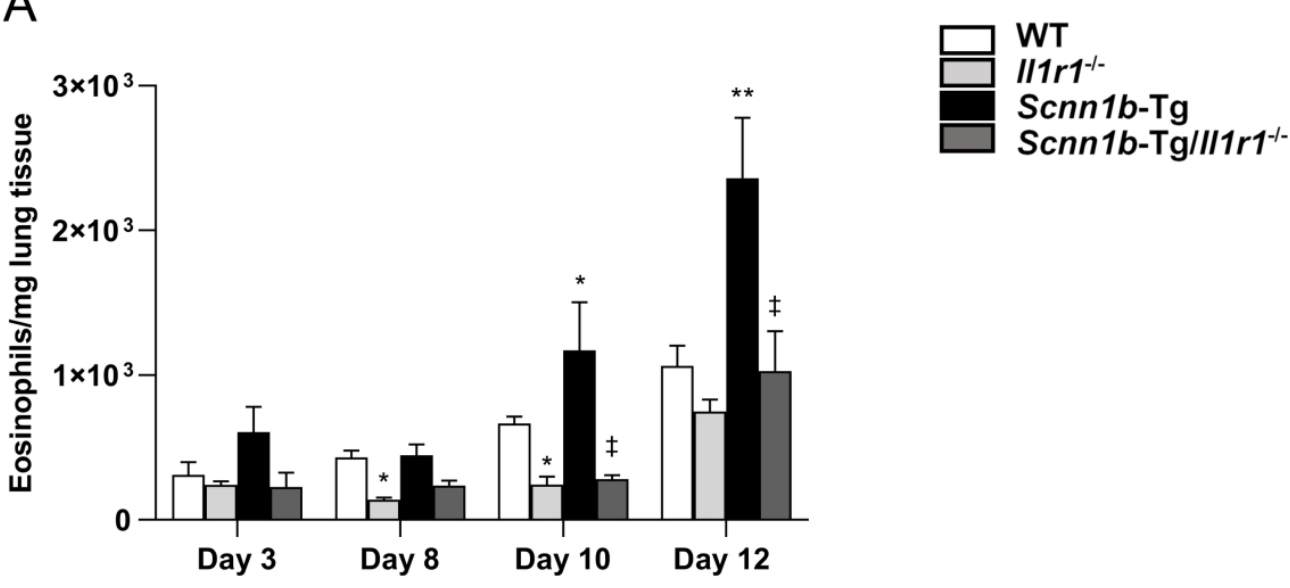

B

C
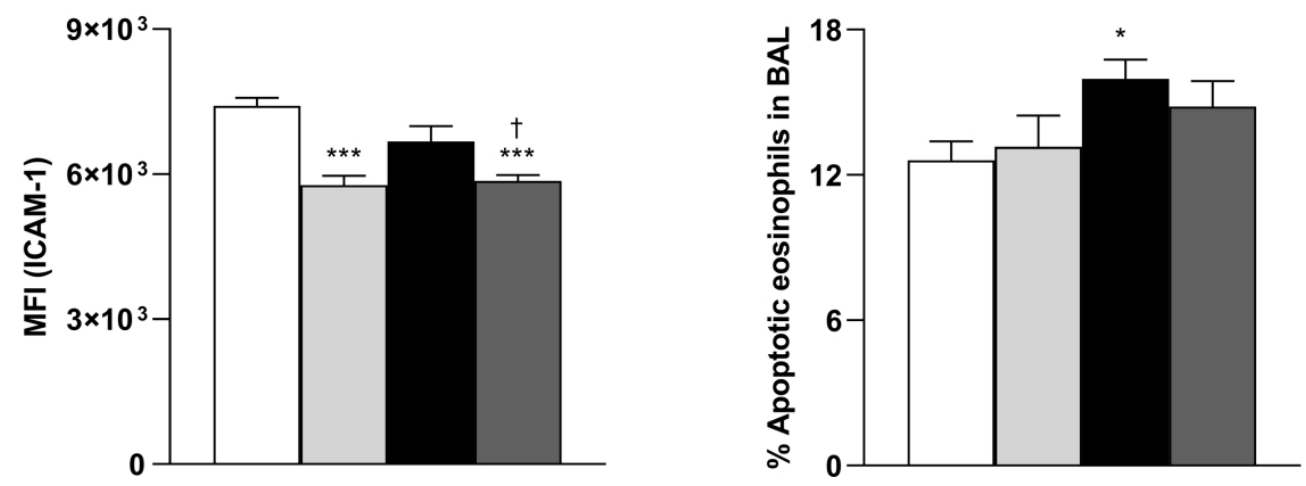

$115 \times 124 \mathrm{~mm}(600 \times 600 \mathrm{DPI})$ 
Figure 5
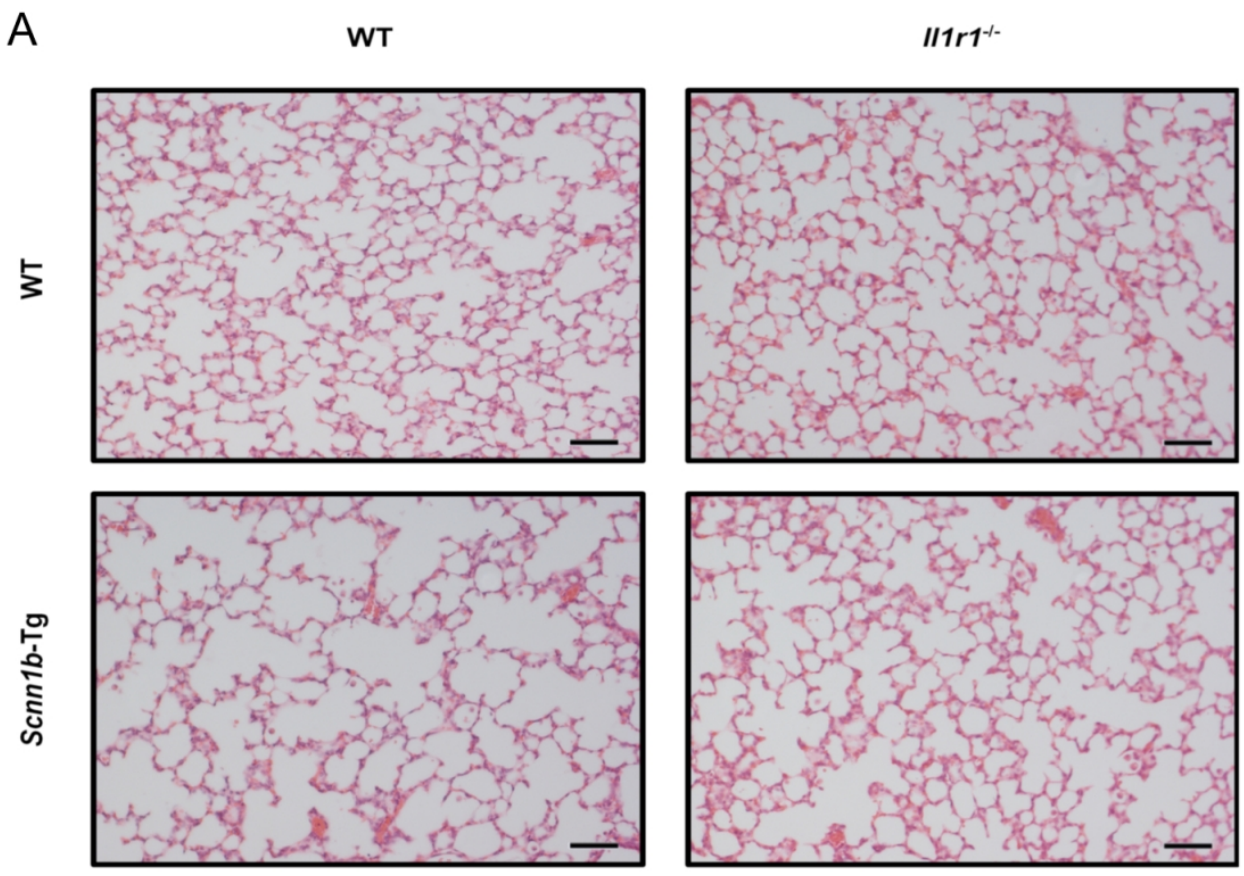

B
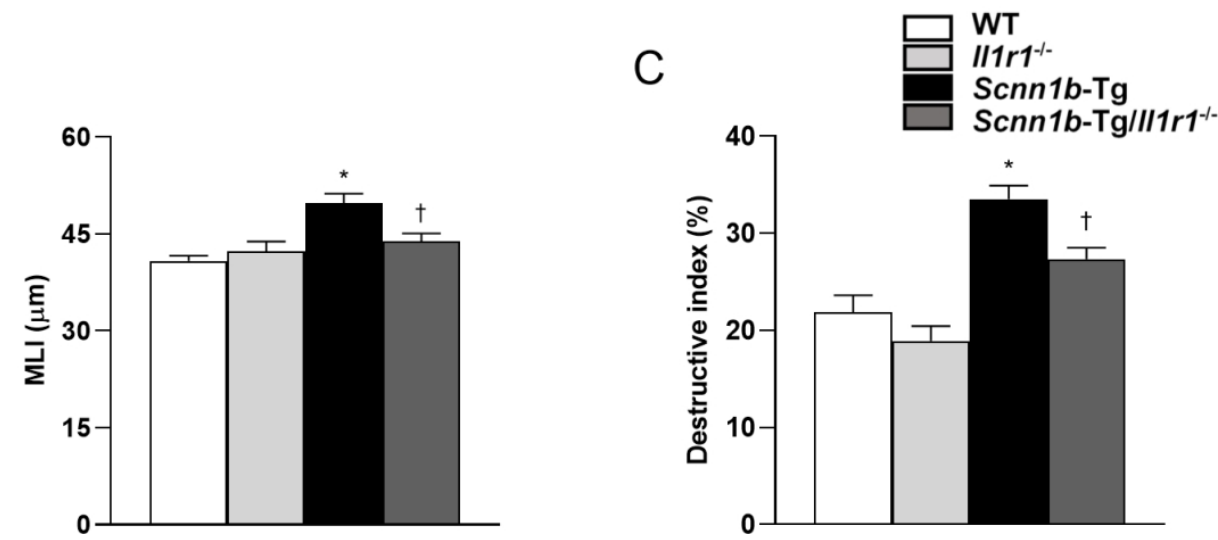

$121 \times 140 \mathrm{~mm}(300 \times 300$ DPI $)$ 
Figure 6

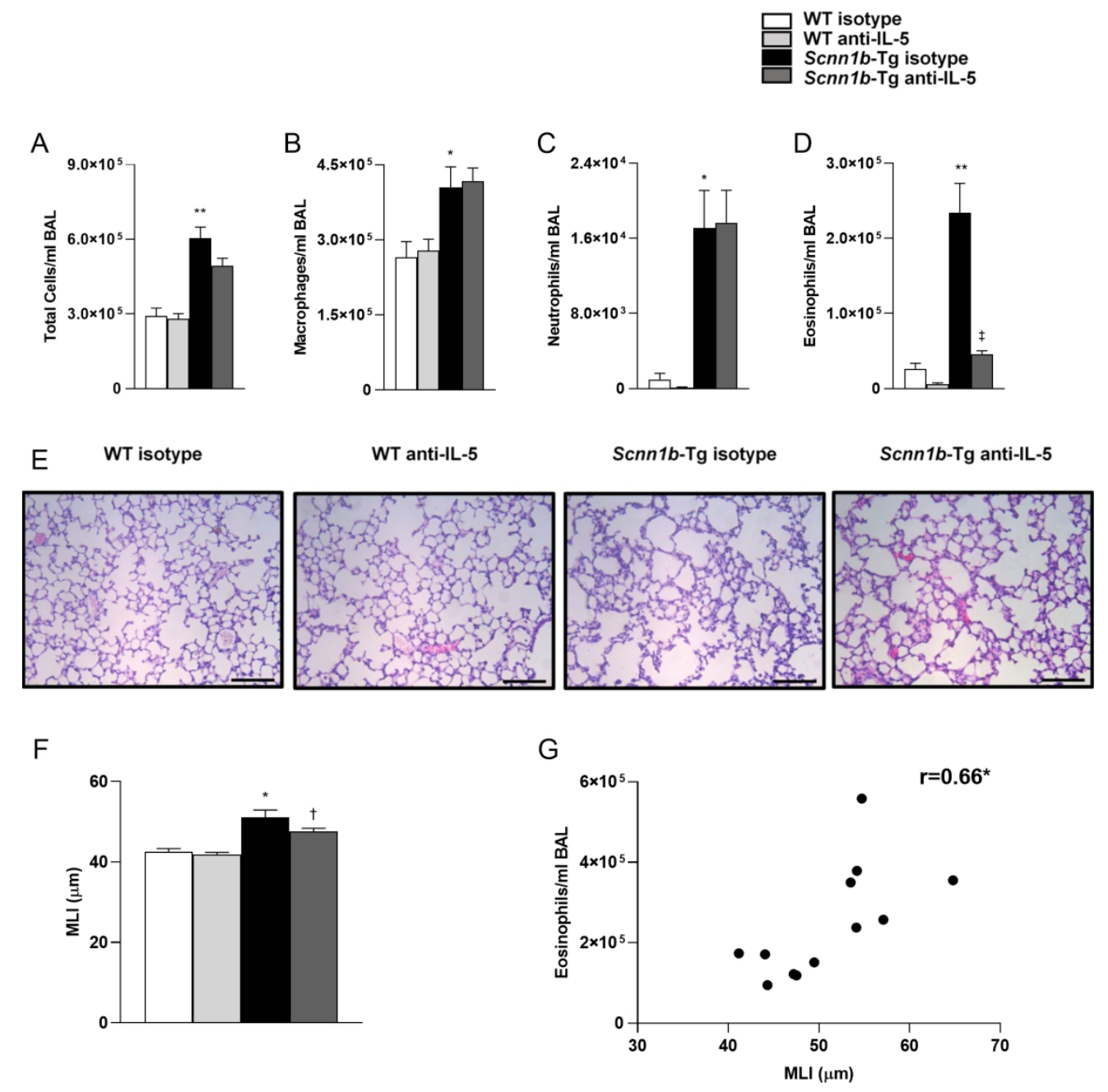

$160 \times 166 \mathrm{~mm}(300 \times 300 \mathrm{DPI})$ 


\section{Lack of IL-1 Receptor Signaling Reduces Spontaneous Airway Eosinophilia in Juvenile Mice with Muco-Obstructive Lung Disease}

Ryan Brown, Michelle Paulsen, Simone Schmidt, Jolanthe Schatterny, Angela Frank, Stephanie Hirtz, Rebecca Delaney, Declan Doherty, Matthias Hagner, Cliff Taggart, Sinéad Weldon and Marcus A. Mall

Online Data Supplement 


\section{SUPPLEMENTAL METHODS}

\section{Flow cytometry}

Multiparameter flow cytometry was performed using an LSRFortessa flow cytometer (BD Biosciences, Heidelberg, Germany). In brief, mice were deeply anesthetized by means of intraperitoneal injection of $120 \mathrm{mg} / \mathrm{kg}$ ketamine and $16 \mathrm{mg} / \mathrm{kg}$ xylazine (Sigma-Aldrich, Taufkirchen, Germany) and exsanguinated. Following vascular perfusion with PBS to remove blood cells, lungs were excised and placed in $1 \mathrm{ml}$ of PBS on ice for immediate processing. Each lung was removed from PBS, placed in a petri dish and minced to pieces no larger than 2-3 mm before being transferred to a $15 \mathrm{ml}$ conical tube with $1 \mathrm{ml}$ of PBS containing $0.2 \%$ collagenase 2 (Worthington Biochemical, Lakewood, NJ) and $30 \mu \mathrm{g} / \mathrm{ml}$ DNase I (Sigma-Aldrich, Taufkirchen, Germany) and incubated for 45 minutes at $37^{\circ} \mathrm{C}$ with gentle rocking. Digested lung solutions were passed through a $100 \mu \mathrm{m}$ mesh to obtain single cell suspensions. Red blood cells were lysed with red blood cell lysis buffer (BD Pharm Lyse, BD Biosciences, Heidelberg, Germany), and single cells were finally resuspended in DMEM/+10\% FCS medium. Cells for flow analysis of apoptotic cell death were obtained from BAL as described below. Cells were counted and up to 2 x $10^{6}$ cells were loaded into 96 well plates to be stained. Before surface staining with specific monoclonal fluorochrome-conjugated antibodies, cells were incubated with Fc Block (BD Biosciences, Heidelberg, Germany). For detection of macrophages $\left(\mathrm{CD}_{4} 5^{+} \mathrm{CD} 11 \mathrm{c}^{+}\right.$SiglecF $\mathrm{F}^{+}$), eosinophils $\left(\mathrm{CD} 45^{+} \mathrm{CD} 11 \mathrm{c}^{\text {low }}\right.$ SiglecF $\left.\mathrm{F}^{+}\right)$, neutrophils $\left(\mathrm{CD} 45^{+} \mathrm{CD} 11 \mathrm{~b}^{+} \mathrm{Ly} 6 \mathrm{G}^{+}\right)$, cells were stained with CD4- fluorescein isothiocyanate (FITC), SiglecF-phycoerythrin (PE), CD11c-PE-CF594, Ly6Gperidinin- chlorophyll-protein complex (PerCp)-Cy5.5, Ly6C-PE-Cy7, CD3-V500, CD11b-BV605, CD45- allophycocyanin (APC), CD8-Alexa Fluor (AF)700. For detection of endothelial cells (CD45CD31 ${ }^{+}$and ICAM-1 staining, cells were stained with CD45-PE-Cy7, CD31-APC and ICAM1-PerCpCy5.5. For analysis of eosinophil apoptotic cell death, cells were stained with Annexin V-PE, CD45AF700, Siglec F-PE, and CD11C-Brilliant violet (BV)421. Cell-surface staining was performed for 30 
minutes at $4^{\circ} \mathrm{C}$. Cell viability was assessed by staining with live/dead fixable efluor780 for 30 minutes prior to sample analysis. All antibodies were obtained from BD Biosciences (Heidelberg, Germany), Biolegend (San Diego, CA) and eBiosciences (San Diego, CA). Flow cytometry was performed immediately after cellular staining with exclusion of nonviable cells and doublets, and data were analyzed with Flow Jo software (v10; TreeStar, Ashland, OR).

\section{BAL cell counts}

Mice were deeply anesthetized by means of intraperitoneal injection of $120 \mathrm{mg} / \mathrm{kg}$ ketamine and $16 \mathrm{mg} / \mathrm{kg}$ xylazine (Sigma-Aldrich, Taufkirchen, Germany) and exsanguinated, and the trachea was cannulated. Lungs were lavaged with PBS by using a weight-adjusted volume of $0.035 \mathrm{ml} / \mathrm{g}$ body weight. This weight-adjusted lavage volume approximates the vital capacity of the developing rodent lung and was used to account for differences in lung size of the age populations of mice included in our study (E1, E2). BAL was repeated twice, both fractions were pooled and centrifuged at $300 \mathrm{~g}$ for 5 minutes at $4^{\circ} \mathrm{C}$. BAL total cell counts were performed, and cell numbers were determined per milliliter of lavage fluid to improve comparability of results from developing mice with different lung sizes, as previously described (E3, E4). BAL differential cell counts were performed from cytospins stained with May-Grünwald Giemsa, with a total of at least 400 cells counted per mouse. 


\section{SUPPLEMENTAL REFERENCES}

E1. Lachmann B, Robertson B, Vogel J. In vivo lung lavage as an experimental model of the respiratory distress syndrome. Acta Anaesthesiol Scand 1980;24:231-6.

E2. Shore SA, Abraham JH, Schwartzman IN, Murthy GG, Laporte JD. Ventilatory responses to ozone are reduced in immature rats. J Appl Physiol 2000;88:2023-30.

E3. Mall MA, Harkema JR, Trojanek JB, Treis D, Livraghi A, Schubert S, Zhou Z, Kreda SM, Tilley SL, Hudson EJ, Neal WKO, Boucher RC. Development of Chronic Bronchitis and Emphysema in bEpithelial Na 1 Channel - Overexpressing Mice. Am J Respir Crit Care Med 2008;177:730-742.

E4. Zhou Z, Treis D, Schubert SC, Harm M, Schatterny J, Hirtz S, Duerr J, Boucher RC, Mall M a. Preventive but not late amiloride therapy reduces morbidity and mortality of lung disease in betaENaC-overexpressing mice. Am J Respir Crit Care Med 2008;178:1245-56. 


\section{SUPPLEMENTAL FIGURES}

Figure E1

A

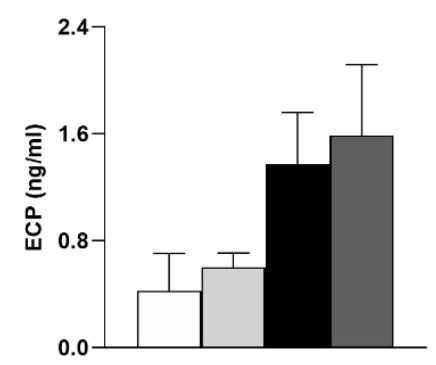

B

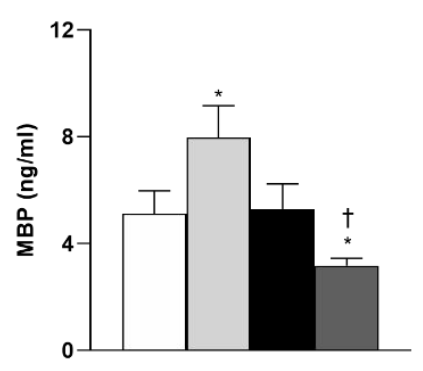

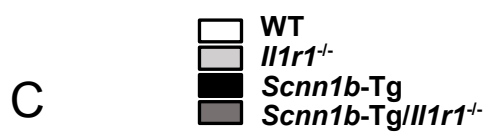

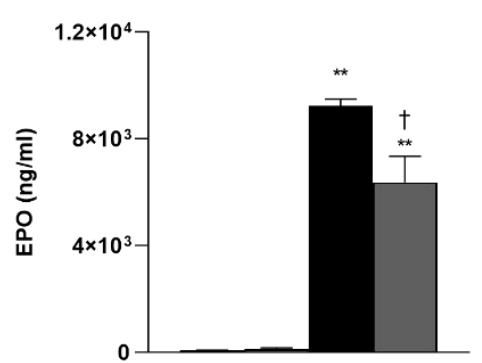

Figure E1. Eosinophil granular protein concentrations in bronchoalveolar lavage (BAL) fluid.

(A-C) Concentrations of eosinophil cationic protein (ECP) (A), major basic protein (MBP) (B), and eosinophil peroxidase (EPO) (C) were determined in BAL fluid from juvenile wild-type (WT), $\| 1 r 1^{--}$, Scnn $1 b-\mathrm{Tg}$ and Scnn $1 b-\mathrm{Tg} / \| 1 \mathrm{r} 1^{--}$mice at 14 days of age. $\mathrm{n}=4-12$ mice per group. ${ }^{*} P<0.05$, ${ }^{* *} P<0.0001$ compared with WT. ${ }^{\dagger} P<0.05$ compared with Scnn $1 b-\mathrm{Tg}$. 